\title{
Glutamine and glutamate as vital metabolites
}

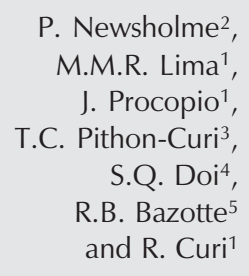

P. Newsholme ${ }^{2}$, M.M.R. Lima ${ }^{1}$, J. Procopio ${ }^{1}$, T.C. Pithon-Curi ${ }^{3}$, S.Q. Doi ${ }^{4}$, R.B. Bazotte ${ }^{5}$ and R. Curi ${ }^{1}$

Key words

- Glutamine

- Glutamate

- Glucose

- Metabolism

- Cell function

\author{
1Departamento de Fisiologia e Biofísica, Instituto de Ciências Biomédicas, \\ ${ }^{2}$ Department of Biochemistry, Conway Institute of Biomolecular and Biomedical \\ Research, University College of Dublin, Belfield, Dublin, Ireland \\ Escola de Educação Física, Universidade Metodista de Piracicaba e Unicastelo, \\ ${ }^{4}$ Department of Medicine, Uniformed Services University of Health Sciences, \\ Bethesda, MD, USA
}

....................

\begin{abstract}
Glucose is widely accepted as the primary nutrient for the maintenance and promotion of cell function. This metabolite leads to production of ATP, NADPH and precursors for the synthesis of macromolecules such as nucleic acids and phospholipids. We propose that, in addition to glucose, the 5-carbon amino acids glutamine and glutamate should be considered to be equally important for maintenance and promotion of cell function. The functions of glutamine/glutamate are many, i.e., they are substrates for protein synthesis, anabolic precursors for muscle growth, they regulate acid-base balance in the kidney, they are substrates for ureagenesis in the liver and for hepatic and renal gluconeogenesis, they act as an oxidative fuel for the intestine and cells of the immune system, provide inter-organ nitrogen transport, and act as precursors of neurotransmitter synthesis, of nucleotide and nucleic acid synthesis and of glutathione production. Many of these functions are interrelated with glucose metabolism. The specialized aspects of glutamine/glutamate metabolism of different glutamineutilizing cells are discussed in the context of glucose requirements and cell function.

Received May 28, 2002

Accepted November 5, 2002

...................

R. Curi

Laboratório de Fisiologia Celula
Departamento de Fisiologia e

05508-900 São Paulo, SP

Fax: +55-11-3091-7285

Research supported by FAPESP,

PRONEX, CNPq and CAPES.
\end{abstract}

\section{Introduction}

Glucose is a vital metabolite which is the main fuel for a large number of cells in the body including neurons and erythrocytes. Glycemia must be maintained at constant levels to avoid severe adverse effects on the body. In the absence of dietary carbohydrate, the maintenance of glycemia is achieved by production of glucose in the liver and kidney and subsequent export to the blood. Also, the flux of glucose between organs is finely controlled by hormones and neurotransmitters. In addition to glucose, glu- neurotransmitters. In additiontoglucose, glu- tamine also plays an essential role for a variety of cell types. This amino acid is a precursor of neurotransmitters and other essential molecules, being indispensable for cell proliferation, immune function and for acid-base balance. More recently, it has been shown that glutamine is also able to regulate gene expression (1) and mitogen-activated protein kinase activation (2). Like glycemia, glutaminemia must also be maintained at constant levels to ensure the functioning of vital systems such as the central nervous system (CNS) and the immune and renal systems. 


\section{General view on the function of glucose metabolism}

Glucose is used by virtually all cells in the body. This metabolite is taken up by cells which use a family of specialized transporters named GLUT- (glucose transporter) 1-7 (3)

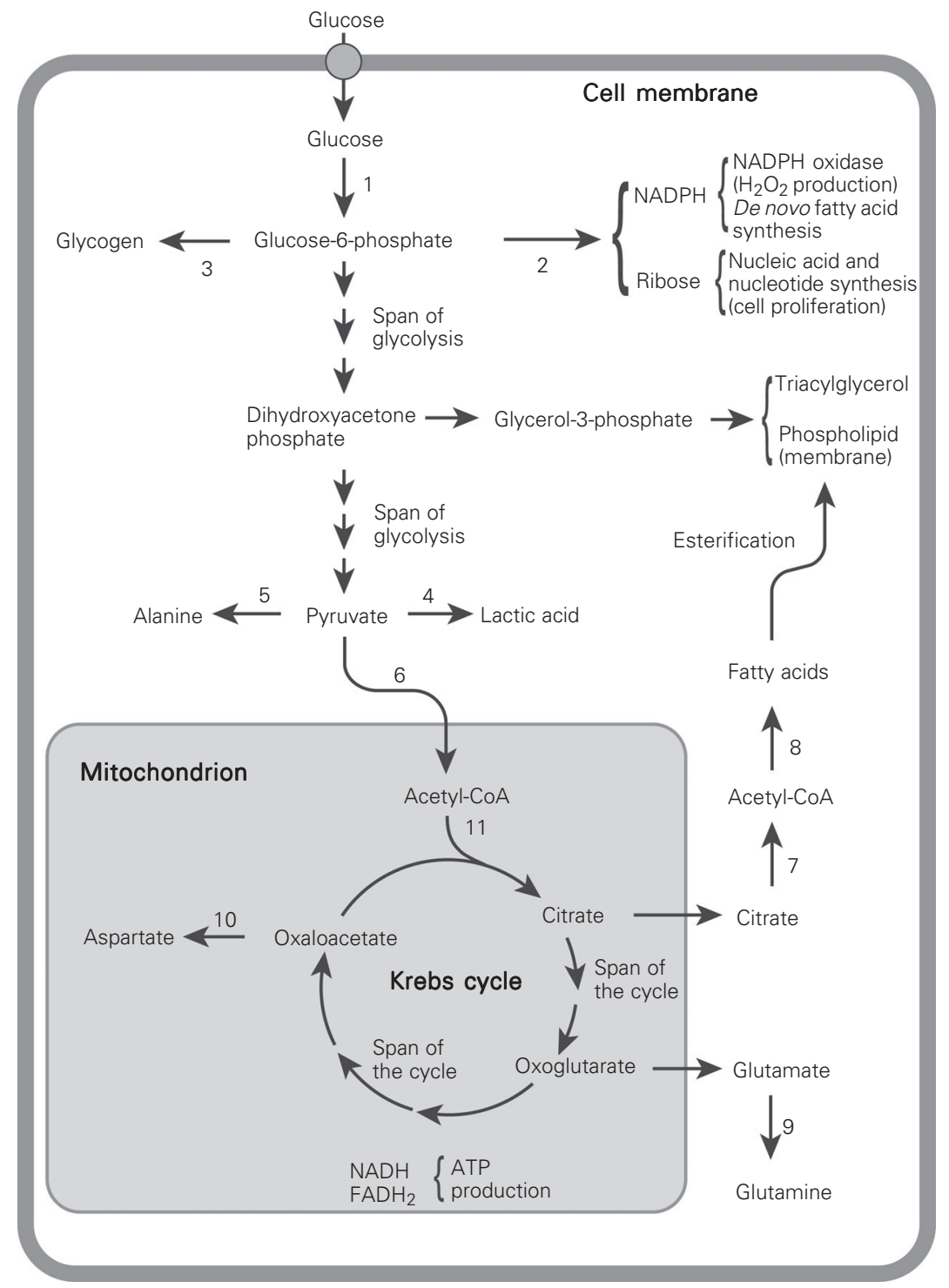

Figure 1. Overview of glucose metabolism in mammalian cells. Glucose-6-phosphate produced from glucose can be converted to glycogen or is metabolized through the pentosephosphate pathway. Glycerol-phosphate is used for triacylglycerol and phospholipid synthesis. Acetyl-CoA is oxidized through the Krebs cycle. Precursors for the synthesis of fatty acids, glutamine and aspartate are generated from this cycle. 1, hexokinase/glucokinase; 2 , pentose-phosphate pathway; 3, glycogen synthesis; 4, lactate dehydrogenase; 5, alanine aminotransferase; 6, pyruvate dehydrogenase; 7, ATP-citrate lyase; 8, fatty acid synthesis; 9, glutamine synthetase; 10 , aspartate aminotransferase; 11 , citrate synthetase.
(Figure 1). Inside the cells glucose can be converted into glucose-6-phosphate by hexokinase (in most tissues) or glucokinase (in the liver and pancreatic islets) (4). Glucose-6phosphate is a precursor of glycogen particularly in the liver and muscle. NADPH generated through the pentose-phosphate pathway is required for NADPH oxidase activity and $\mathrm{H}_{2} \mathrm{O}_{2}$ production and also for de novo fatty acid synthesis $(5,6)$. Ribose-5-phosphate produced in the same pathway is used for nucleotides and nucleic acid synthesis (7). Another glucose-derived metabolite, glycerol-3-phosphate (Figure 1), is the backbone of the main lipid storage molecule, triacylglycerol, or phospholipids (which are important components of cell membranes). Glycolysis-derived pyruvate can be converted to lactate and alanine or it generates acetyl-CoA through pyruvate dehydrogenase - a key step in the Krebs cycle. This cycle provides both NADH/FADH ${ }_{2}$ for ATP synthesis through the respiratory chain and precursors for synthesis of other metabolites, such as fatty acids starting from citrate, aspartate from oxaloacetate and glutamate/glutamine from oxoglutarate (8). Carbon dioxide may be the major end-product of glucose metabolism in many cells but lactate or alanine may also be major end-products in conditions of low oxygen tension or alternative cellular requirements. While ATP generation may be a primary reason for glucose metabolism in many cells, the supply of metabolic intermediates for use in biosynthetic reactions is an important additional consideration (Figure 1).

The metabolism of glucose is required by most cells for survival, proliferation, and differentiation but may also play additional roles such as promotion of insulin secretion by pancreatic $\beta$-cells and cytolytic activity of phagocytes (monocytes, macrophages and neutrophils).

\section{Overview of glutamine metabolism}

The physiological importance of the amino acid L-glutamine for promoting and 
maintaining cell function is now widely accepted (Figure 2). The importance of glutamine to cell survival and proliferation in vitro was first reported by Ehrensvard et al. in 1949 (9) but was more fully described by Eagle et al. in 1956 (10). Glutamine had to be present in 10- to 100-fold excess of any other amino acid in culture and could not be replaced by glutamic acid or glucose. This work led to the development of the first tissue culture medium that contained essential growth factors, glucose, 19 essential and nonessential amino acids at approximately physiological concentrations, and a high concentration of glutamine $(2 \mathrm{mmol} / \mathrm{l})$.

It is now known that a large number of tissues and cells in the body utilize glutamine at high rates and that glutamine utilization is essential for their function. These tissues and cells include kidney, intestine, liver, specific neurons in the CNS, cells of the immune system, and pancreatic B-cells (see Refs. 11 and 12 for further details).

L-glutamine is important as a precursor for peptide and protein synthesis, amino sugar synthesis, purine and pyrimidine and thus nucleic acid and nucleotide synthesis, and also provides a source of carbons for oxidation in some cells. However, the immediate product of glutamine metabolism in most cells is L-glutamate, which is produced by the action of glutaminase, an enzyme found at high concentrations and associated with the mitochondria in cells which readily utilize glutamine. L-glutamate is the most abundant intracellular amino acid (reported concentrations vary between 2 and $20 \mathrm{mM}$ ) and L-glutamine is the most abundant extracellular amino acid in vivo $(0.7 \mathrm{mM}$ compared to an approximate L-glutamate concentration of $20 \mu \mathrm{M})$. L-glutamate cannot readily cross cell membranes because it has an overall charge of -1 at $\mathrm{pH} 7.4$ and amino acid transporters capable of transporting glutamate into the cell are present at low density in the plasma membrane with the exception of specialized glutamate-metabolizing cells located in the CNS (13). L-glutamate appears to be at the crossroads of amino acid metabolism, where it can donate its amino group for new amino acid synthesis (transamination) or can lose the amino group, as $\mathrm{NH}_{4}^{+}$, via deamination to 2-oxoglutarate (see Figure 2). In some tissues and cells such as liver, skeletal muscle or astrocytes, glutamate and $\mathrm{NH}_{4}^{+}$may be combined by the action of glutamine synthetase to produce glutamine. This glutamine is then exported from the cell.

L-glutamine is required for a number of specific biochemical reactions, as outlined above. However, of greater physiological importance to many cells, L-glutamine is a precursor of L-glutamate. This review will highlight the critical role of L-glutamine and L-glutamate metabolism for the maintenance and promotion of cell function in a diverse selection of cell types.

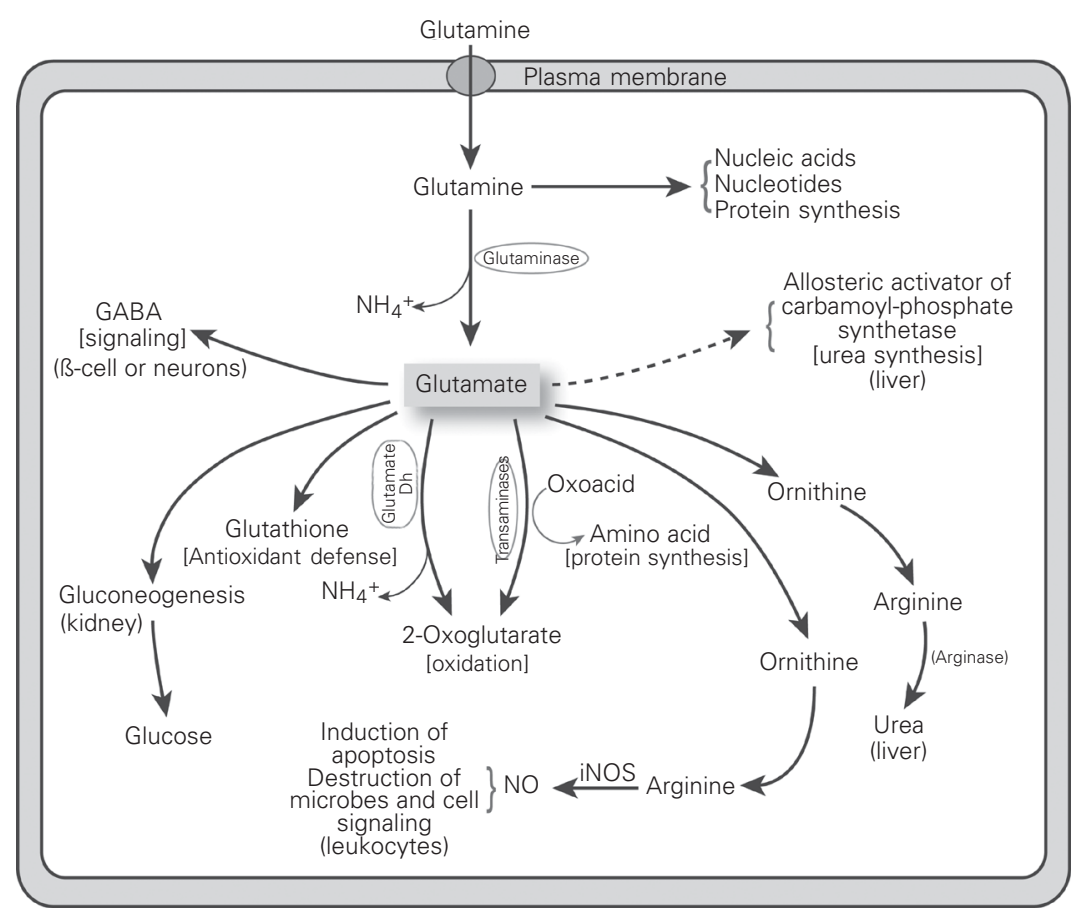

Figure 2. Overview of glutamine and glutamate metabolism in mammalian cells. Glutamate is produced from glutamine through glutaminase activity. Glutamate can then be converted to $\gamma$-amino butyric acid (GABA), ornithine, 2-oxoglutarate, glucose or glutathione. The probable functions of the glutamate products are indicated as well as the cells or organs where the metabolic pathway preferentially occurs. NO, nitric oxide; iNOS, inducible nitric oxide synthase; glutamate Dh, glutamate dehydrogenase. 


\section{Glutamine/glutamate in the kidney}

Glutamine is quantitatively the most important donor of $\mathrm{NH}_{3}$ in the kidney (Figure $3 \mathrm{~A})$. The $\mathrm{NH}_{3}$ is cleaved from glutamine by the action of phosphate-dependent glutaminase, which is subjected to $\mathrm{pH}$ regulation (14). $\mathrm{NH}_{3}$ is exported to the lumen of the collecting tubule where it combines with exported $\mathrm{H}^{+}$to form $\mathrm{NH}_{4}{ }^{+}$, which is lost to the urine. $\mathrm{H}^{+}$is created from carbonic acid, which dissociates to form $\mathrm{HCO}_{3}{ }^{-}$and $\mathrm{H}^{+}$. $\mathrm{HCO}_{3}{ }^{-}$subsequently enters the circulation where it is important for the maintenance of blood $\mathrm{pH}$. Therefore, glutamine metabolism in the kidney is essential for acid-base buffering in the plasma $(14,15)$. The carbon skeleton of glutamate in the kidney, created by the action of glutaminase, is converted via formation of 2-oxoglutarate, succinate, fumarate, malate and oxaloacetate to phosphoenolpyruvate (or malate to pyruvate directly) and then participates in gluconeogenesis (Figure $3 \mathrm{~A}$ ). Glucose produced by this pathway provides up to $25 \%$ of circulating plasma glucose in vivo (16). Renal gluconeogenesis is especially important in conditions where the blood concentration of ketone bodies increases, causing acidosis. This occurs, for instance, during long periods of hypoglycemia or diabetes. Hepatic gluconeogenesis from amino acids (mainly alanine) is gradually replaced by renal gluconeogenesis. Under these conditions, glucose produced by the kidney can account for up to $50 \%$ of circulating plasma glucose (17).

\section{Glutamine/glutamate in the intestine}

Glutamine is quantitatively the most important fuel for intestinal tissue. It is metabolized to glutamate by phosphate-dependent glutaminase. Glutamate undergoes transamination with pyruvate generating L-alanine and 2-oxoglutarate. The latter metabolite is then oxidized in the tricarboxylic acid (TCA) cycle generating malate, which, by the ac- tion of $\mathrm{NADP}^{+}$-dependent malic enzyme, generates pyruvate (Figure 3B). The NADH and $\mathrm{FADH}_{2}$ generated via this pathway are used for electron donation to the electron transporting chain in the mitochondria and thus promote ATP synthesis. The L-alanine produced in this pathway is exported to the hepatic portal vein for transport to the liver (18). Glutamine is recognized as an important dietary component for the maintenance of gut integrity (19) and reduces the degree of derangement induced by mechanical intestinal obstruction (20). As a result, glutamine administration reduces bacterial translocation (21), being beneficial to critically ill and other patients $(22,23)$. In fact, glutamine has been shown to improve various aspects of medical nutritional care of patients with gastrointestinal disease or cancer, burn victims, postsurgical patients, and low birth weight neonates (24-26). This amino acid also normalizes the AIDS-associated increased intestinal permeability (27).

\section{Glutamine/glutamate in the liver}

The liver is the central site for nitrogen metabolism in the body (Figure 3C) (28). Nitrogen is transported from peripheral tissues (principally from muscle and lung) to the central organs as glutamine, plus alanine and aspartate if the glutamine is taken up and metabolized by the intestine (11). Glutamine can be cleaved by glutaminase to yield glutamate and $\mathrm{NH}_{3}$. The mitochondrial carbamoyl-phosphate synthetase I (CPS I) can then catalyze the following reaction:

$$
\begin{gathered}
2 \mathrm{ATP}+\mathrm{HCO}_{3}^{-}+\mathrm{NH}_{3} \longrightarrow \\
\text { carbamoyl-phosphate }+2 \mathrm{ADP}+\mathrm{Pi}
\end{gathered}
$$

The enzyme is allosterically activated by $\mathrm{N}$-acetylglutamate and thus may be indirectly regulated by glutamate concentration. Carbamoyl-phosphate may combine with ornithine in the urea cycle to produce citrulline, which is subsequently converted to argininosuccinate and then to arginine (Fig- 

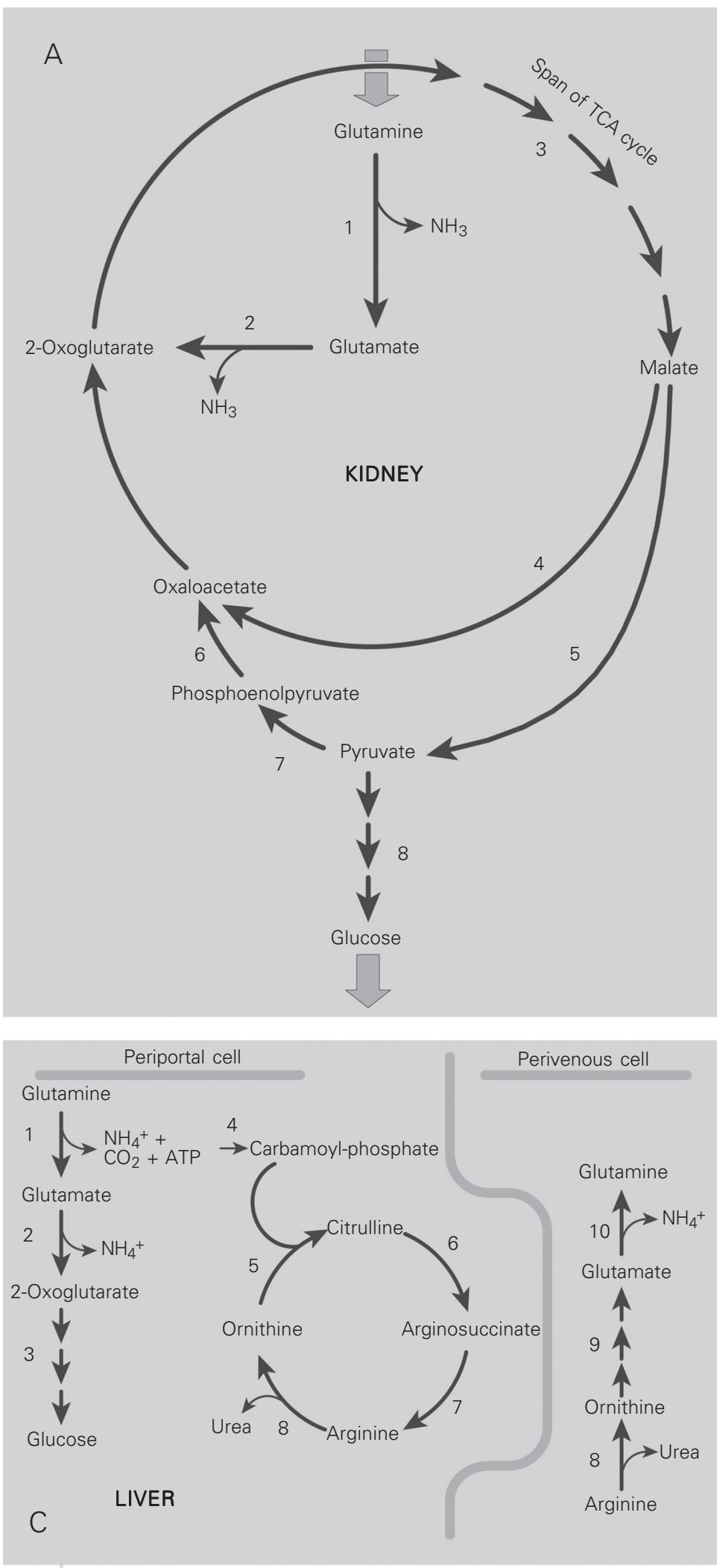

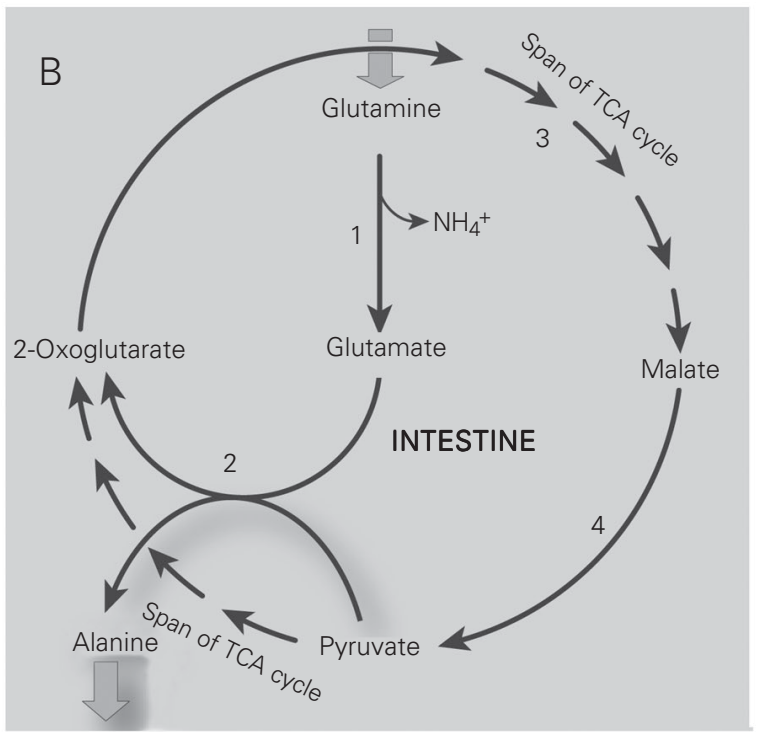

Figure 3. A, Pathway of glutamine metabolism in the kidney. 1, Phosphate-dependent glutaminase; 2, glutamate dehydrogenase; 3, reactions of the tricarboxylic acid (TCA) cycle; 4, NADHmalate dehydrogenase; 5, NADP+'-dependent malic enzyme; 6 , pyruvate carboxylase; 7 , pyruvate kinase; 8 , pathway of gluconeogenesis (cytosol). B, Pathway of glutamine metabolism in the intestine. 1, Phosphate-dependent glutaminase; 2, alanine aminotransferase; 3 , reactions of the TCA cycle; 4, NADP+dependent malic enzyme. C, Pathway of glutamine metabolism in the periportal and perivenous cells of the liver. Glutamine nitrogen is utilized for urea synthesis while the carbon skeleton is used for glucose synthesis by periportal cells. Under conditions in which arginine availability is not limiting, glutamine is synthesized in the perivenous cells. 1, Phosphate-dependent glutaminase; 2, glutamate dehydrogenase; 3, enzymes of the gluconeogenesis pathway; 4, carbamoyl-phosphate synthetase; 5 , ornithine transcarbamoylase; 6 , argininosuccinate synthetase; 7, argininosuccinase; 8 , arginase; 9, enzymes of glutamate synthesis; 10 , glutamine synthetase. 
ure 3C). Arginine is subsequently cleaved by arginase to produce urea and ornithine. In mammalian tissues another isoform of CPS exists, termed CPS II. This is a large multifunctional cytosolic protein (29) that catalyzes the formation of carbamoyl-phosphate:

2 ATP $+\mathrm{HCO}_{3}^{-}+$glutamine $+\mathrm{H}_{2} \mathrm{O} \longrightarrow$ carbamoyl-phosphate + glutamate +2 ADP $+\mathrm{Pi}$

The reaction is also involved in the synthesis of the N3 atom of pyrimidine nucleotides, whereas the amide of glutamine is used directly for the formation of the N3 and N9 atoms of purines.

Glutamine metabolism is partitioned in space within the liver, where glutamine is taken up by the periportal cells of the liver in which there is a relatively high glutaminase activity and the ammonia produced is directed toward CPS $(30,31)$.

Glutamate that has been produced in the periportal cells may be further metabolized to produce other amino acids by transamination or may enter the TCA cycle as an anaplerotic substrate or may enter the pathway of gluconeogenesis via formation of phosphoenolpyruvate from oxaloacetate (Figure 3C). Thus, gluconeogenesis from glutamine may be a major consumer of glutamate-derived carbon in the liver, resulting in the formation and export of glucose (32).

Glutamine formation and release from the liver, on the other hand, occurs mainly in the perivenous region (Figure 3C). The hepatocytes in this area are rich in glutamine synthetase (32). The substrate(s) for glutamine synthesis are of course glutamate and $\mathrm{NH}_{4}{ }^{+}$. Glutamate may be produced via glucose conversion to 2-oxoglutarate and subsequent conversion to glutamate via glutamate dehydrogenase. However, recent data have suggested that arginine catabolism may provide glutamate for the glutamine synthetase reaction (33). The glutamine synthetase reaction is energy requiring and is described below: glutamate $+\mathrm{NH}_{4}{ }^{+}+\mathrm{ATP} \longrightarrow$ glutamine + $\mathrm{ADP}+\mathrm{Pi}$

Liver glutamine metabolism plays an important role in controlling ammonia levels in venous blood. The synthesis and hydrolysis of glutamine are intermediate steps in urea formation, since the $K_{\mathrm{M}}$ of CPS for ammonia is high $(2 \mathrm{mM})$, whereas glutamine synthase $K_{\mathrm{M}}$ for ammonia is much lower $(0.3$ $\mathrm{mM})$. Thus, the liver first removes ammonia present in low concentrations in the blood to form glutamine, which passes through the circulation and reaches the organ again. The key enzymes of urea formation are present in higher amounts in periportal and proximal perivenous hepatocytes, whereas glutamine synthase occurs only in distal perivenous hepatocytes (34-36).

\section{Glutamine/glutamate in the CNS}

The major transmitter at excitatory synapses in the CNS is glutamate, whereas inhibitory signals are carried by $\gamma$-amino butyric acid (GABA; 37,38). The existence of a glutamine/glutamate cycle in the CNS has been recently confirmed (39). Glutamine is synthesized from glutamate in the astrocytes so as to return the glutamate that is removed from the synaptic cleft after release from the presynaptic neuron. The neuron will readily convert the astrocyte-derived glutamine to glutamate via glutaminase, to complete the cycle. The cycle is energy dependent since ATP is consumed in the synthesis of glutamine from glutamate. In the human cortex the cycle appears to account for $80 \%$ of the energy derived from glucose oxidation (40, 41).

\section{Glutamine/glutamate in cells of the immune system}

It is now widely accepted that glutamine is utilized at high rates by isolated cells of the immune system such as lymphocytes, mac- 
rophages and neutrophils (42-44). Although the activity of the first enzyme responsible for the metabolism of glutamine, phosphatedependent glutaminase, is high in these cells, the rate of oxidation is low. Much of the glutamine is converted to glutamate, aspartate (via TCA cycle activity), lactate and, under appropriate conditions, $\mathrm{CO}_{2}$. Glutamine has been reported to enhance many functional parameters of immune cells such as T-cell proliferation, B-lymphocyte differentiation, macrophage phagocytosis, antigen presentation and cytokine production (4549), plus neutrophil superoxide production and apoptosis $(50,51)$.

Although glutamine may be required by these cells as a precursor for nucleic acid and nucleotide synthesis, the provision of glutamate may be equally important in cells of the immune system. Glutamate is involved in a number of key functions, in addition to amino acid transamination, in lymphocytes, macrophages and neutrophils. Provision of $\mathrm{NADPH}$, via the action of $\mathrm{NADP}^{+}$-dependent malic enzyme, which catalyzes the conversion of malate (which is derived from glutamate via formation of 2-oxoglutarate, succinate, and fumarate) to pyruvate, may be one of its functions (52). NADPH is required for biosynthetic reactions such as fatty acid synthesis or for the production of free radicals such as $\mathrm{O}_{2}^{-}$or nitric oxide by NADPH oxidase and inducible nitric oxide synthase, respectively (45). NADPH is also required by glutathione reductase and as such plays an important role in increasing reduced glutathione concentration, thus enhancing antioxidant defenses and delaying apoptosis via stabilization of neutrophil mitochondria (53). Indeed, the greater proportion of glutamine metabolized to lactate in neutrophils compared to macrophages or lymphocytes may be due to significantly higher demands for NADPH in the neutrophils.

Glutamate is also required as a precursor for ornithine synthesis in macrophages and monocytes. This pathway connects with the urea cycle and ultimately results in formation of arginine and thus of a substrate for inducible nitric oxide synthase (54). Extracellular arginine is depleted by active secretion of the enzyme arginase by macrophages and monocytes, cells which subsequently become dependent on intracellularly derived arginine for nitric oxide synthesis (54). Glutamate may also serve as a precursor for glutathione synthesis and as such may play a direct role in antioxidant defenses (55) in these cells (Figure 2).

\section{Glutamine/glutamate in the pancreatic ß-cell}

Glutamine has been reported to enhance glucose- or leucine-stimulated insulin secretion from pancreatic $\beta$-cells (located in the endocrine islets of Langerhans), but does not promote insulin secretion by itself due to tight regulation of glutamate dehydrogenase activity $(56,57)$. Glutamine may act as an anaplerotic substrate in the $\beta$-cell, via formation of glutamate and 2-oxoglutarate, subsequently stimulating a catalytic enhancement of glucose oxidation (58). Nutrient metabolism is intimately connected with the process of insulin secretion from the $\beta$-cell. Nutrient metabolism results in an increase in the ATP/ ADP ratio, a closure of $\mathrm{K}^{+}{ }_{\text {ATP }}$ channels, membrane depolarization, opening of voltagedependent calcium channels, an increase in cytosolic $\mathrm{Ca}^{2+}$ concentration, and promotion of insulin exocytosis (59). The mitochondria play a critical role, via oxidative phosphorylation, in increasing the ATP/ADP ratio. However, the mitochondria are also important for the generation of metabolic coupling factors that act to further enhance insulin secretion in a $\mathrm{K}^{+}{ }_{\text {ATP }}$ channel-independent manner $(60,61)$. One of these metabolic coupling factors has been identified as glutamate $(62,63)$. Glutamate is also important in the $\beta$-cell as a substrate for the enzyme glutamic acid decarboxylase, which produces the signaling molecule GABA (64). GABA 
production and secretion may be important for the regulation of insulin secretion in intact islets of Langerhans (65).

Recent reports have highlighted the important regulatory role of glutamate dehydrogenase in $\beta$-cells. Mutations in the GTP allosteric site within the enzyme, which result in a lower affinity for the allosteric inhibitor GTP, have been shown to result in elevated insulin secretion and associated hyperinsulinemia in affected individuals (66, 67). Thus, the metabolic importance of glutamate concentration and glutamate dehydrogenase activity with respect to insulin secretion in $\beta$-cells is now firmly established. However, the metabolic interplay between glucose and amino acid-derived glutamate and the implication for the regulation of $B-$ cell insulin secretion has yet to be fully determined (68).

\section{Glutamine metabolism in skeletal muscle}

Muscle tissue is a major site for glutamine synthesis in the human body and contains over $90 \%$ of the whole-body glutamine pool. Quantitative studies in humans have demonstrated that, in the postabsorptive state, $60 \%$ of the amino acids released comprise alanine plus glutamine $(7,69,70)$. In resting muscle, six amino acids are metabolized: leucine, isoleucine, valine, asparagine, aspartate and glutamate (71). These amino acids provide the amino groups and probably the ammonia required for synthesis of glutamine and alanine, which are released in excessive amounts in the postabsortive state and during ingestion of a protein-containing meal. The release of glutamine from skeletal muscle is also stimulated during stress conditions such as injury and burns $(8,72)$. Only leucine and isoleucine molecules can be oxidized in muscle after being converted to acetyl-CoA. The other carbon skeletons are used for de novo synthesis of TCA cycle intermediates and glutamine. The rate of
TCA cycle flux and so oxidative metabolism is limited by the concentration of the TCA cycle intermediates. The dramatic decline in intramuscular glutamate at the start of exercise with the concomitant increase in intramuscular alanine suggests that glutamate is an important anaplerotic precursor $(73,74)$.

\section{Concluding remarks}

Glucose is generally considered to be the primary nutrient for cell function, acting as an oxidative fuel in most cells but it also has an important role in the supply of precursors for biosynthetic reactions. It is primarily utilized through the pathways of glycolysis and subsequently the TCA cycle. Flux through these pathways is tightly controlled via allosteric effectors and reversible phosphorylation of key metabolic enzymes.

Glutamine is the most abundant amino acid found in blood plasma (75). It is a major transporter of nitrogen from sites of glutamine synthesis (skeletal muscle, liver, lung) to sites of utilization, including kidney, intestine, neurons, cells of the immune system and, under appropriate conditions of acidbase balance, liver (76).

Given the importance of plasma glutamine to cell function, it is not surprising that dietary supplementation or parenteral nutrition can improve the outcome for critically ill patients, postsurgical patients or those recovering from injury $(45,77)$.

Glutamine itself may act as a key precursor for nucleic acids and nucleotides in glutamine-consuming cells, but in many physiological circumstances acts to provide glutamate, which appears to promote a wider array of metabolic functions compared to glutamine (Figure 2). Ultimately glutamine and glutamate metabolism is exquisitely related to the function of the glutamine-requiring cell, for example provision of $\mathrm{NH}_{3}$ for acid buffering and carbon for glucose production in the kidney, partial oxidation and alanine production in the intestine, provi- 
sion of $\mathrm{NH}_{3}$ for urea synthesis and carbon for glucose production in the liver, neurotransmitter synthesis in the brain, NADPH and free radical production plus antioxidant defenses, as well as DNA and protein synthesis in cells of the immune system, and metabolic coupling factors that synergistically promote insulin secretion from the pancreatic $\beta$-cell. The pathways of glutamine and glutamate metabolism have adapted to cater for the unique function of the glutamine-utilizing cell (Figures 2 and 3 ) and thus could not be replaced by other metabolic inputs if they fail. In this respect, we should consider glutamine and glutamate metabolism to be as important as glucose metabolism in the cell due to their wide variety of metabolic roles that are critical for cell function.

\section{Acknowledgments}

We thank the Health Research Board of Ireland, Enterprise Ireland, and The British Council for the support of research and travel between our laboratories.

\section{References}

1. Pithon-Curi TC, Levada AC, Lopes LR, Doi SO \& Curi R (2002). Glutamine plays a role in superoxide production and the expression of p47phox, p22 ${ }^{\text {phox }}$ and gp91 phox in rat neutrophils. Clinical Science, 103:403-408.

2. Rhoads M (1999). Glutamine signaling in intestinal cells. Journal of Parenteral and Enteral Nutrition, 23: 38-40.

3. Inna A, Belyantseva IA, Henry J, Curi R, Gregory I, Fronlenkov GI \& Bechara K (2000). Expression and localization of prestin and the sugar transporter GLUT-5 during development of electromotility in cochlear outer hair cells. Journal of Neuroscience, 20: 1-5.

4. Carpinelli AR, Picinato MC, Stevanato E, Oliveira HR \& Curi R (2002). Insulin secretion induced by palmitate. A process fully dependent on glucose concentration. Diabetes and Metabolism (in press).

5. Curi R, Newsholme P, Pithon-Curi TC, Pires-de-Melo M, Garcia C, Homem-de-Bittencourt Jr PI \& Guimarães ARP (1999). Metabolic fate of glutamine in lymphocytes, macrophages and neutrophils. Brazilian Journal of Medical and Biological Research, 32: 15-21.

6. Pithon Curi TC, Pires de Melo M, Palanch AC, Miyasaca CK \& Curi R (1998). Percentage of phagocytosis, production of $\mathrm{O}_{2} \cdot-, \mathrm{H}_{2} \mathrm{O}_{2}$ and $\mathrm{NO}$ and antioxidant enzyme activities of rat neutrophils in culture. Cell Biochemistry and Function, 16: 43-49.

7. Newsholme P, Curi R, Pithon-Curi TC, Murphy CJ, Garcia C \& Piresde-Melo M (1999). Glutamine metabolism by lymphocytes, macrophages and neutrophils. Its importance in health and disease. Journal of Nutritional Biochemistry, 10: 316-324.

8. Newsholme EA, Newsholme P, Curi R \& Ardawi MSM (1988). A role for muscle in the immune system and its importance in surgery, trauma, sepsis and burns. Nutrition, 4: 261-268.

9. Ehrensvard G, Fischer A \& Stjernholm R (1949). Protein metabolism of tissue cells in vitro. The chemical nature of some obligate factors of tissue cell nutrition. Acta Physiologica Scandinavica, 18: 218-230.

10. Eagle H, Washington CL, Levy M \& Cohen L (1966). The populationdependent requirement by cultured mammalian cells for metabolite, which they can synthesize. II. Glutamic acid and glutamine; aspartic acid and asparagine. Journal of Biological Chemistry, 10: 4994-4999.

11. Young VR \& Ajami AM (2001). Glutamine: The emperor or his clothes? Journal of Nutrition, 131: 2449-2459.

12. Curi R (2000). Glutamina - Metabolismo e Aplicações Clínicas e no
Esporte. Editora Sprint, Rio de Janeiro, RJ, Brazil.

13. Matthews JC \& Anderson KJ (2002). Recent advances in amino acid transporters and excitatory amino acid receptors. Current Opinion in Clinical Nutrition and Metabolic Care, 5: 77-84.

14. Gstraunthaler G, Holcomb T, Feifel E, Liu W, Spitaler N \& Curthoys NP (2000). Differential expression and acid-base regulation of glutaminase mRNAs in gluconeogenic LLC-PK(1)-FBPase(+) cells. American Journal of Physiology, 278: F227-F237.

15. Curthoys NP \& Gstraunthaler G (2001). Mechanism of increased renal gene expression during metabolic acidosis. American Journal of Physiology, 281: F381-F390.

16. Stumvoll M, Perriello G, Meyer C \& Gerich J (1999). Role of glutamine in human carbohydrate metabolism in kidney and other tissues. Kidney International, 5: 778-779.

17. Owen OE, Felig P, Morgan AP, Wahren J \& Cahill Jr GF (1969). Liver and kidney metabolism during prolonged starvation. Journal of Clinical Investigation, 48: 574-583.

18. Kimura RE, Lapine TR, Johnston J \& llich JZ (1988). The effect of fasting on rat portal venous and aortic blood glucose, lactate, alanine and glutamine. Pediatric Research, 23: 241-244.

19. Neu J, DeMarco V \& Li N (2002). Glutamine: clinical applications and mechanisms of action. Current Opinion in Clinical Nutrition and Metabolic Care, 5: 69-75.

20. Chang $T$, Lu R \& Tsai L (2001). Glutamine ameliorates mechanical obstruction-induced intestinal injury. Journal of Surgical Research, 95: 133-140.

21. Erbil $Y$, Berber E, Ozarmagan S, Seven R, Eminoglu L, Calis A, Olgac $V$ \& Gurler N (1999). The effects of sodium deoxycholate, lactulose and glutamine on bacterial translocation in common bile duct ligated rats. Hepatogastroenterology, 46: 2791-2795.

22. Newsholme EA, Newsholme P \& Curi R (1987). The role of the citric acid cycle in cells of the immune system and its importance in sepsis, trauma and burns. Biochemical Society Symposia, 54: 145162.

23. Boelens PG, Nijveldt RJ, Houdijk APJ, Meijer S \& Leeuwen PAMV (2001). Glutamine alimentation in catabolic state. Journal of Nutrition, 131: 2569-2577.

24. Savy GK (2002). Glutamine supplementation. Heal the gut, help the 
patient. Journal of Infusion Nursing, 25: 65-69.

25. Gismondo MR, Drago L, Fassina MC, Vaghi I, Abbiati R \& Grossi E (1998). Immunostimulating effect of oral glutamine. Digestive Diseases and Sciences, 43: 1752-1754.

26. Neu J (2001). Glutamine in the fetus and critically ill low birth weight neonate: metabolism and mechanism of action. Journal of Nutrition, 131: 2585-2589.

27. Thomson $A B$, Keelan $M$, Thiesen $A$, Clandinin $M T$, Ropeleski $M$ \& Wild GE (2001). Small bowel review: diseases of the small intestine. Digestive Diseases and Sciences, 46: 2555-2566.

28. Haussinger D (1989). Glutamine metabolism in the liver: overview and current concepts. Metabolism, 38: 14-17.

29. Hewagama A, Guy HI, Vickrey JF \& Evans DR (1999). Functional linkage between the glutaminase and synthetase domains of carbamoyl-phosphate synthetase. Journal of Biological Chemistry, 274: 28240-28245.

30. Curthoys NP \& Watford M (1995). Regulation of glutaminase activity and glutamine metabolism. Annual Review of Nutrition, 15: 133159.

31. Häussinger D (1990). Nitrogen metabolism in liver: structural and functional organization and physiological relevance. Biochemical Journal, 267: 281-290.

32. De-Souza HM, Borba-Murad GR, Ceddia RB, Curi R, VerdanegaPeicher M \& Bazotte RB (2001). Rat liver responsiveness to gluconeogenic substrates during insulin-induced hypoglycemia. Brazilian Journal of Medical and Biological Research, 34: 771-777.

33. O'Sullivan D, Brosnan JT \& Brosnan ME (1998). Hepatic zonation of the catabolism of arginine and ornithine in the perfused liver. Biochemical Journal, 330: 627-632.

34. Gebhardt R \& Mecke D (1983). Heterogeneous distribution of glutamine synthetase among rat liver parenchymal cells in situ and in primary culture. EMBO Journal, 2: 567-570.

35. Haussinger D (1986). Regulation of hepatic ammonia metabolism: the intercellular cycle. Advances in Enzyme Regulation, 25: 159-180.

36. Jungermann K \& Katz N (1989). Functional specialization of different hepatocyte populations. Physiological Reviews, 69: 708-764.

37. Raol YH, Lynch DR \& Brooks-Kayal AR (2001). Role of excitatory amino acids in developmental epilepsies. Mental Retardation and Developmental Disabilities Research Reviews, 7: 254-260.

38. Fantana G, Taccola G, Galante J, Salis S \& Raiteri M (2001). AMPAevoked acetylcholine release from cultured spinal chord motoneurones and its inhibition by GABA and glycine. Neuroscience, 106: 183-191.

39. Behar KL \& Rothman DL (2001). In vivo NMR studies of glutamateGABA-glutamine cycling in rodent and human cortex: the central role of glutamine. Journal of Nutrition, 131: 2498-2504.

40. Rothman DL, Sibson NR, Hyder F, Shen J, Behar KL \& Shulman RG (1999). In vivo nuclear magnetic resonance spectroscopy studies on the relationship between the glutamate-glutamine neurotransmitter cycle and functional neuroenergetics. Philosophical Transactions of the Royal Society of London. B, Biological Sciences, 354: 11651177.

41. Shulman RG \& Rothman DL (1998). Interpreting functional imaging studies in terms of neurotransmitter cycling. Proceedings of the National Academy of Sciences, USA, 95: 11993-11998.

42. Ardawi MSM \& Newsholme EA (1983). Glutamine metabolism in lymphocytes of the rat. Biochemical Journal, 212: 835-842.

43. Newsholme P, Curi R, Gordon S \& Newsholme EA (1986). Metabolism of glucose, glutamine, long-chain fatty acids and ketone bodies by murine macrophages. Biochemical Journal, 239: 121-125.

44. Curi TC, De Melo MP, De Azevedo RB, Zorn TMT \& Curi R (1997).
Glutamine utilization by rat neutrophils: presence of phosphatedependent glutaminase. American Journal of Physiology, 273: C1124-C1129.

45. Newsholme P (2001). Why is L-glutamine metabolism important to cells of immune system in health, postinjury, surgery or infection? Journal of Nutrition, 131: 2515-2522.

46. Wells SM, Kew S, Yaqoob P, Wallace F \& Calder P (1999). Dietary glutamine enhances cytokine production by murine macrophages. Nutrition, 15: 881-884

47. Kew S, Wells SM, Yaqoob P, Wallace FA, Miles EA \& Calder PC (1999). Dietary glutamine enhances murine T-lymphocyte responsiveness. Journal of Nutrition, 129: 1524-1531.

48. Yeh SL, Yeh CL, Lin MT, Lo PN \& Chen WJ (2001). Effects of glutamine-supplemented total parenteral nutrition on cytokine prodution and T cell population in septic rats. Journal of Parenteral and Enteral Nutrition, 25: 269-274.

49. Moinard C, Chauveau B, Walrand S, Felgines C, Chassagne J, Caldefie F, Cynober LA \& Vasson MP (1999). Phagocyte functions in stressed rats: comparison of modulation by glutamine, arginine and ornithine 2-oxoglutarate. Clinical Science, 97: 59-65.

50. Garcia C, Pithon-Curi TC, De Lourdes Firmano M, Pires de Melo M, Newsholme P \& Curi R (1999). Effects of adrenaline on glucose and glutamine metabolism and superoxide production by rat neutrophils. Clinical Science, 96: 549-555.

51. Pithon-Curi TC, Schumaker IR, Freitas JJS, Lagranha C, Newsholme P, Palanch AC, Doi SQ \& Curi R (2002). Glutamine delays spontaneous apoptosis in neutrophils. American Journal of Physiology (in press).

52. Newsholme P, Costa Rosa LFBP, Newsholme EA \& Curi R (1996). The importance of fuel metabolism to macrophage function. Cell Biochemistry and Function, 14: 1-10.

53. O'Neill AJ, O'Neill S, Hegarty NJ, Coffee RN, Gibbons N, Brady H, Fitzpatrick JM \& Watson RW (2000). Glutathione depletion-induced neutrophil apoptosis is caspase 3 dependent. Shock, 14: 605-609.

54. Murphy C \& Newsholme P (1998). Importance of glutamine metabolism in murine macrophages and human monocytes to L-arginine biosynthesis and rates of nitrite or urea production. Clinical Science, 95: 397-407.

55. Gleeson M \& Bishop NC (2000). Modification of immune responses to exercise by carbohydrate, glutamine and anti-oxidant supplements. Immunology and Cell Biology, 78: 554-561.

56. Gao ZY, Li G, Najafi H, Wolf BA \& Matschinsky FM (1999). Glucose regulation of glutaminolysis and its role in insulin secretion. Diabetes, 48: 1535-1542.

57. Tanizawa Y, Nakai K, Sasaki T, Anno T, Ohta Y, Inoue H, Matsuo K, Koga M, Furukawa S \& Oka Y (2002). Unregulated elevation of glutamate dehydrogenase activity induces glutamine-stimulated insulin secretion. Diabetes, 51: 712-717.

58. Meglasson MD, Manning CD, Najafi H \& Matschinsky FM (1987). Fuel stimulated insulin secretion by clonal hamster beta cell line HIT T-15. Diabetes, 36: 477-484.

59. McClenaghan NH \& Flatt PR (1999). Engineering cultured insulinsecreting pancreatic ß-cell lines. Journal of Molecular Medicine, 77: 235-243.

60. Wollheim CB \& Maechler P (2002). B-cell mitochondria and insulin secretion: messenger role of nucleotides and metabolites. Diabetes, 51: 37-42.

61. Maechler P \& Wollheim CB (2001). Mitochondrial function in normal and diabetic ß-cells. Nature, 414: 807-812.

62. Maechler P \& Wollheim CB (1999). Mitochondrial glutamate acts as a second messenger in glucose-induced insulin exocytosis. Nature, 
402: $685-689$.

63. Wollheim CB (2000). Beta-cell mitochondria in the regulation of insulin secretion: a new culprit in type-II diabetes. Diabetologia, 43: 265-277.

64. Rubi $B$, Ishihara $H$, Hegardt FG, Wollheim CB \& Maechler $P$ (2001). GAD65-mediated glutamate decarboxylation reduces glucose-stimulated insulin secretion in pancreatic ß-cells. Journal of Biological Chemistry, 276: 36391-36396.

65. Winnock F, Ling Z, De Proft R, Dejonghe S, Schuit F, Gorus F \& Pipeleers D (2002). Correlation between GABA release from rat islet ß-cells and their metabolic state. American Journal of Physiology, 282: E937-E942.

66. Yorifugi T, Muroi J, Uematsu A, Hiramatsu H \& Momoi T (1999). Hyperinsulinism-hyperammonemia syndrome caused by mutant glutamate dehydrogenase accompanied by novel enzyme kinetics. Human Genetics, 104: 476-479.

67. Stanley CA, Fang J, Kutyna K, Hsu BY, Ming JE, Glaser B \& Poncz M (2000). Molecular basis and characterization of the hyperinsulinism/ hyperammonia syndrome: predominance of mutations in exons 11 and 12 of the glutamate dehydrogenase gene. Diabetes, 49: 667673.

68. Brennan L, Shire A, Hewage C, Malthouse JPG, McClenaghan N, Flatt P \& Newsholme P (2002). L-alanine oxidation is required for insulin secretion in the clonal ß-cell line BRIN BD11. Diabetes, 51: 1714-1721.

69. Felig P (1975). Amino acid metabolism in man. Annual Review of
Biochemistry, 44: 933-955.

70. Newsholme EA \& Parry-Billings M (1990). Properties of glutamine release from muscle and its importance for the immune system. Journal of Parenteral and Enteral Nutrition, 14: 63-67.

71. Wagenmakers AJ (1998). Muscle amino acid metabolism at rest and during exercise: role in human physiology and metabolism. Exercise and Sport Sciences Reviews, 26: 287-314.

72. Hammarqvist F, Ejesson B \& Wernerman J (2001). Stress hormones initiate prolonged changes in the muscle amino acid pattern. Clinical Physiology, 21: 44-50.

73. Gibala MJ, MacLean DA, Graham TE \& Saltin B (1997). Anaplerotic processes in human skeletal muscle during brief exercise dynamic. Journal of Physiology, 502: 703-713.

74. Bowtell JL \& Bruce M (2002). Glutamine: An anaplerotic precursor. Nutrition, 18: 222-224

75. Williamson DH \& Brosnan JT (1974). Concentrations of metabolites in animal tissues. In: Bergmeyer HU (Editor), Methods in Enzymatic Analysis. Academic Press, New York and London.

76. Newsholme EA, Newsholme P, Curi R, Crabtree B \& Ardawi MSM (1989). Glutamine metabolism in different tissues. Its physiological and pathological importance. In: Kinney JM \& Borum PR (Editors), Perspectives in Clinical Nutrition. Urban, Schwarzenberg, Baltimore, MD, USA

77. Lacey JM \& Wilmore DW (1990). Is glutamine a conditionally essential amino acid? Nutrition Reviews, 48: 297-309. 